\title{
Antiangiogenic Treatment Concepts in Gynecologic Oncology
}

\author{
M. Eichbaum, C. Mayer, E. Bischofs, J. Reinhardt, J. Thum and C. Sohn \\ Departments of Obstetrics and Gynecology, University of Heidelberg, Heidelberg,
}

Germany

\section{Introduction}

Gynecologic malignancies count for about 80,000 of all new cancer diagnoses in women in the United States (Jemal et al., 2010). In the US almost 20,000 patients a year are diagnosed with epithelial ovarian cancer, 11,000 with cervical cancer and 42,000 with endometrial cancer (Jemal et al., 2010). A relevant part of these tumor situations are found in an earlystage disease setting, for instance most of all newly diagnosed endometrial cancers. But frequently there is no possibility for an early-stage diagnosis and the tumor is already advanced when primarily detected, like in the majority of all cases with epithelial ovarian cancer (EOC).

Though tumor biology and standard treatment concepts are different for all three entities, there is a common need for new therapeutic approaches to improve the patients' outcome. Many preclinical studies have suggested that antiangiogenic strategies are beneficial against these cancers (Delli Carpini, 2010). One reason may be the fact that these tumors are able to form large single tumor nodulations during intraabdominal spread or local progression with hypoxic cores triggering tumor-associated neo-angiogenesis (Bryant et al., 2010). Furthermore, the frequently seen phenomenon of peritoneal carcinosis, closely related to gynecologic malignancies, induces angiogenesis to preserve nutritive supply to all metastatic tumor nodes (Fagotti et al., 2010, Figure 1).

Since Folkman first proposed the strategy of targeting the tumor vasculature as a novel therapeutic strategy, considerable progress has been made to understand the underlying mechanisms of angiogenesis (Folkman, 1971). The control of angiogenesis is under the influence of both pro- and anti-angiogenesis factors. Of these, vascular endothelial growth factor (VEGF) and its family of receptors play a key role in the regulation of angiogenesis. The VEGF gene family consists of several members including placenta growth factor (PIGF), VEGF-A, VEGF-B, VEGF-C and VEGF-D, but VEGF-A (often referred to as VEGF) is the dominant protein (Ferrara, 2003). The VEGF receptor family consists of three members including VEGFR-1(Flt-1), VEGFR-2 (KDR or Flk-1), and VEGFR-3 (Flt-4). Given the key role of VEGF and its family of receptors in regulating angiogenesis, inhibitors of both VEGF and its receptors are actively being developed as anti-cancer therapies. To inhibit the VEGF pathway two different options are used:

1. VEGF ligand inhibition by antibodies or soluble receptors

2. VEGF receptor inhibition by tyrosine kinase inhibitor (TKIs) or receptor antibodies 
Several further antiangiogenic targets beside the VEGF pathway are identified and explored (Figure 2).

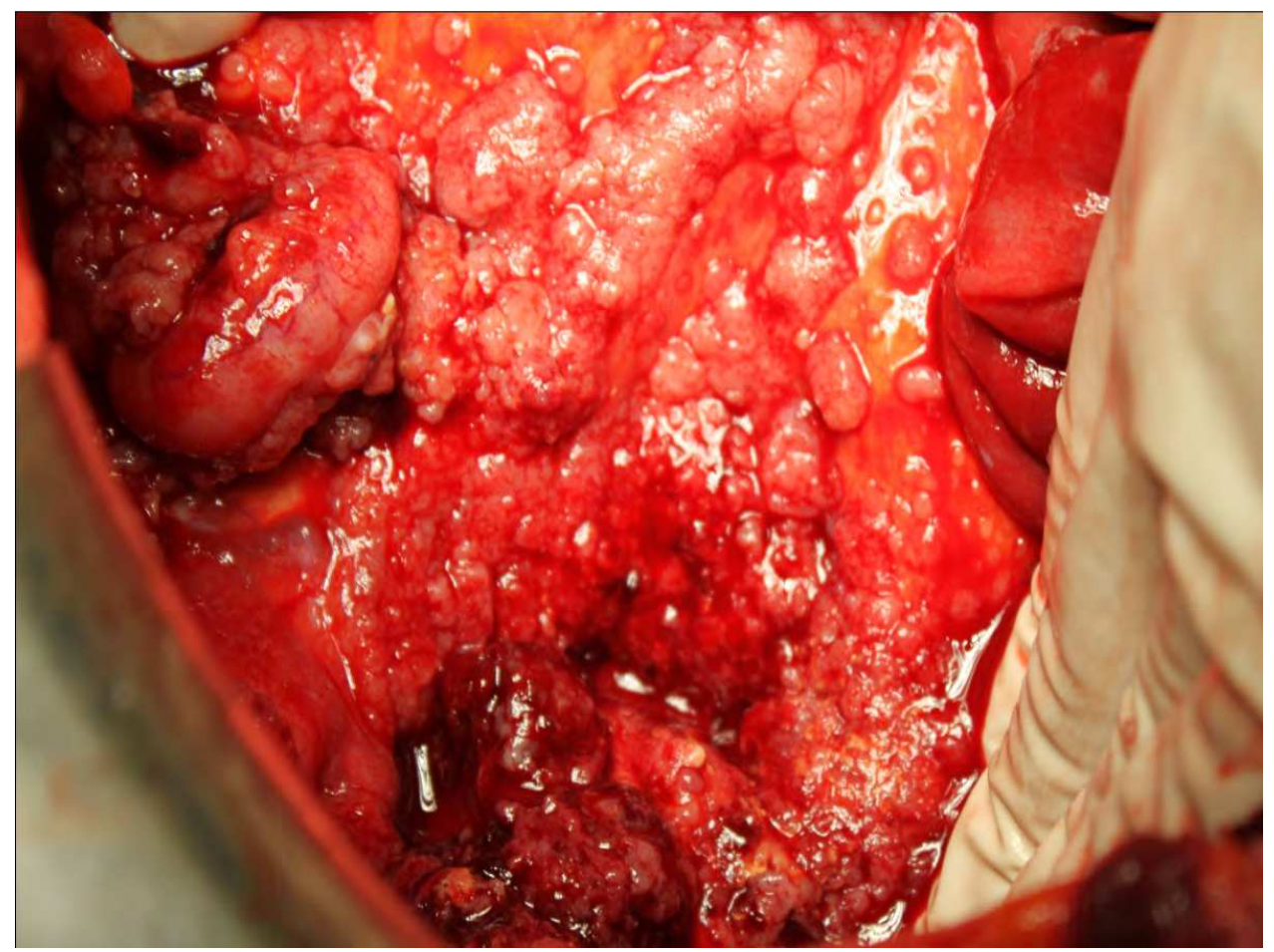

Fig. 1. Peritoneal carcinosis and Angiogenesis.

The clinical evaluation of antiangiogenic drugs revealed new, unique toxicity profiles and potential side-effects, such as hypertension, proteinuria and GI-toxicities that have so far not been in the focus of the oncologist and need to be understood and closely considered during therapy. However, under careful and responsible advise most of the established and documented treatment concepts can be performed without difficulties.

In summary, antiangiogenic drugs are reasonable and promising new therapeutic strategies under clinical investigation. Subsequently, current antiangiogenic treatment strategies against the three main gynecologic malignancies ovarian cancer, cervical cancer and endometrial cancer will be presented and discussed.

\section{Ovarian cancer}

\subsection{Background}

In the US about 21,880 women a year develop a malignant tumour of the ovary. The incidence of ovarian carcinoma has remained unchanged in the last few decades. With more than 13,850 deaths, it is the fifth highest cause of cancer-related mortality in women. Symptoms of the disease usually develop at a very late stage. For this reason about $70 \%$ of patients are already in an advanced stage of the tumor at the time of diagnosis (FIGO III or 


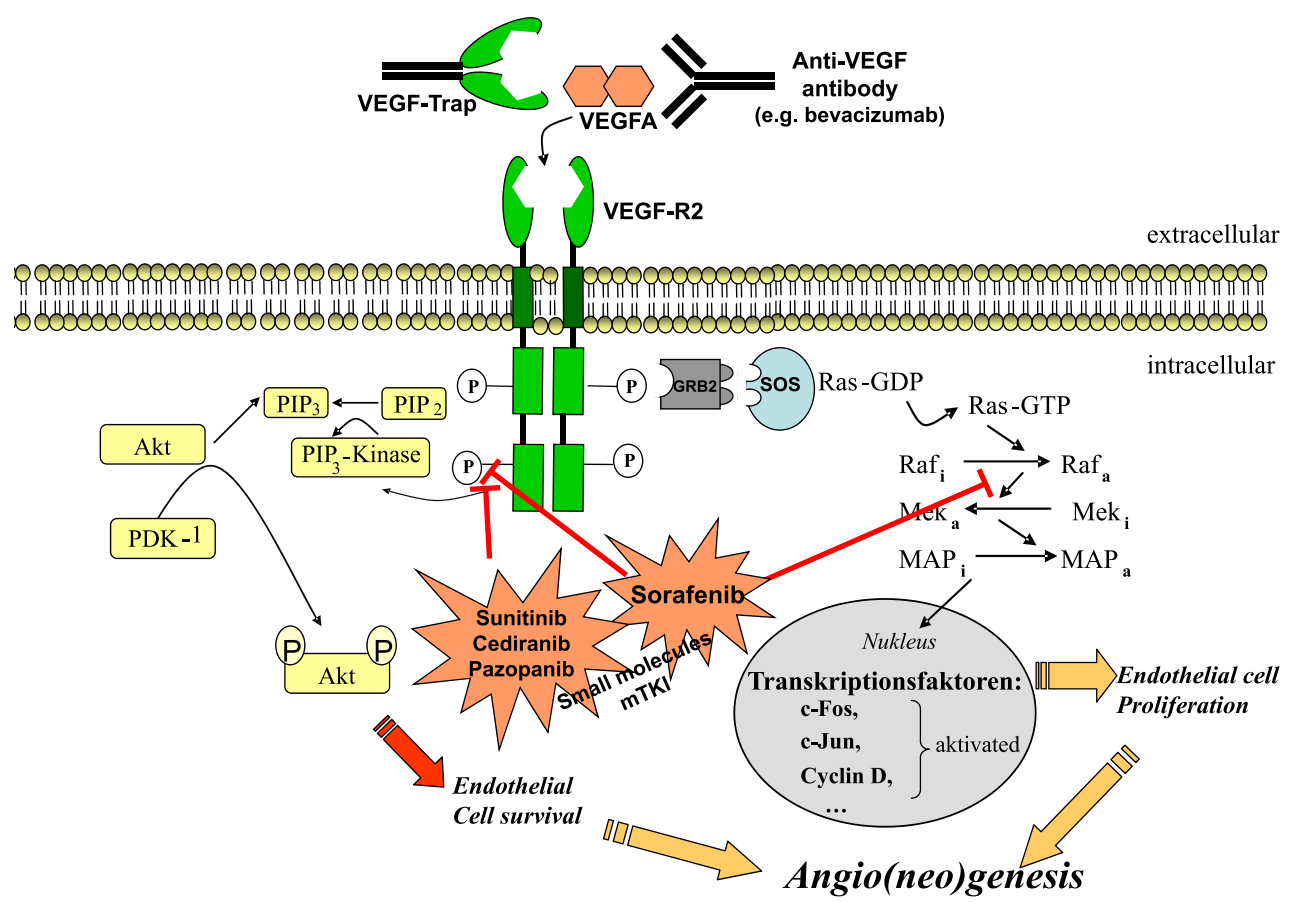

Fig. 2. Molecular mechanisms in tumor-associated angiogenesis and main targets of current investigations.

IV). Surgical tumor removal is the primary treatment. Whether and to what extent residual tumour formation is present postoperatively is the deciding factor in the subsequent prognosis for the patient. After surgery, chemotherapy involving paclitaxel plus carboplatin is generally indicated in the event of an initially advanced tumour stage (McGuire et al., 1999; McGuire et al., 2001; Parmar et al., 2003). Despite improved surgical procedures and a high primary response to chemotherapy, about $70 \%$ of patients with advanced ovarian carcinoma develop a tumor relapse and die from the disease.

Angiogenesis is a critical pathway in the development and progression of ovarian cancer. Therefore, identification and development of novel agents with limited toxicity that target mechanisms of tumor progression such as angiogenesis are of high priority. Data from numerous preclinical and clinical trials support the assumption of VEGF/VEGFR, PDGFR as well as FDGF as target molecules for the treatment of ovarian cancer (Burger, 2010). Beyond these currently intensively investigated targets, further antiagiogenic pathways are explored, such as angiopoetin or vascular disrupting agents (VDA) (Theo et al., 2010; Zweifel et al., 2011).

\section{Anti-angiogenic agents in investigational clinical trials}

Several anti-angiogenic agents are evaluated in investigational clinical trials to improve the therapy of recurrent and also primary ovarian cancer. Results from a number of phase I and phase II trials are available and also phase III trials have been performed and have led to first reported data, in particular the GOG 218 as well as the ICON-7-trial. 


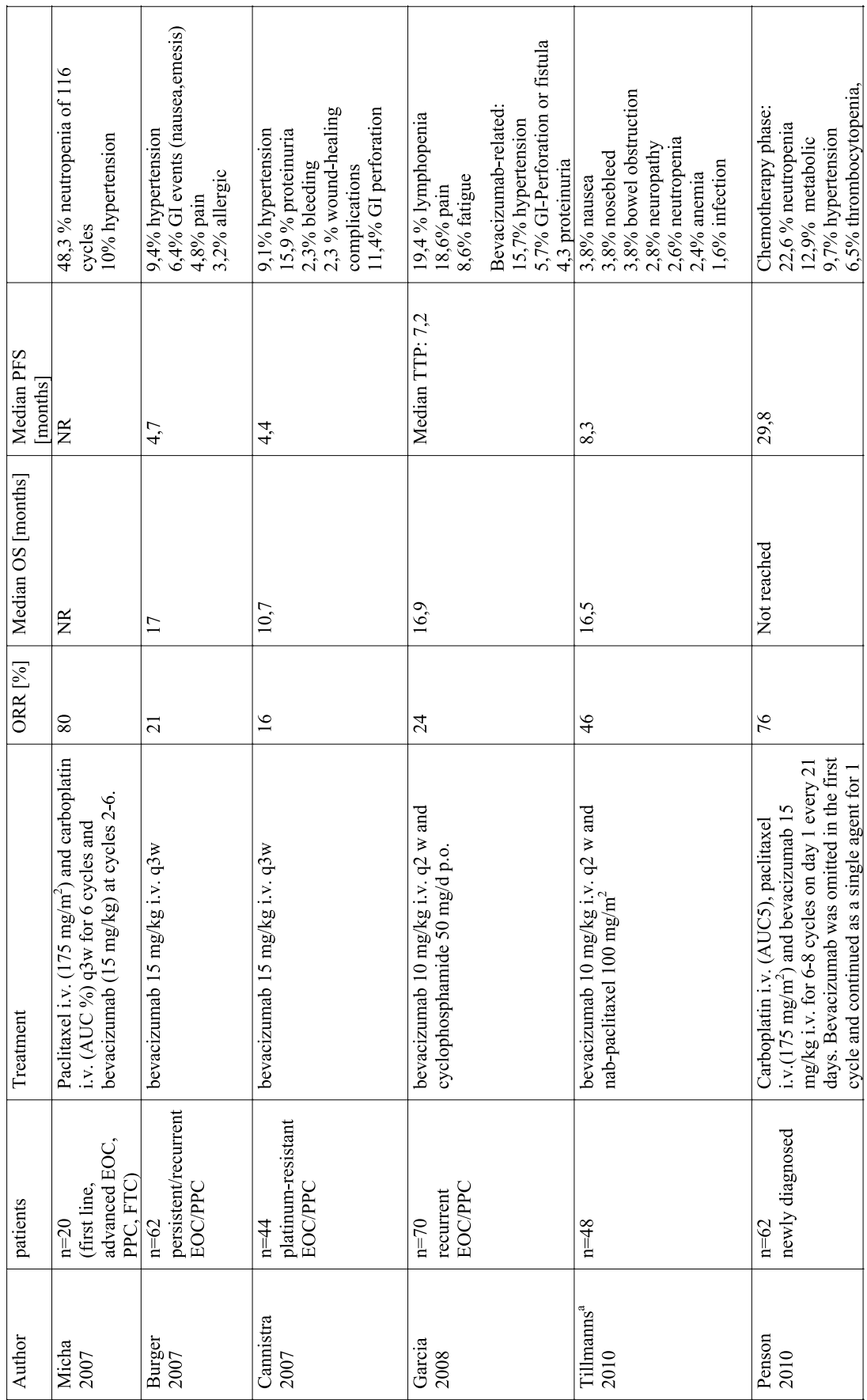

Table 1. Antiangiogenic drugs currently under investigation in EOC. 


\section{Bevacizumab}

The most clinical experiences have been collected targeting VEGF with the recombinant humanized monoclonal anti-VEGF antibody (bevacizumab, avastin ${ }^{\circledR}$ ).

Several phase II studies showed efficacy and tolerability as well in the palliative as in the adjuvant setting. Recently, bevacizumab in combination with the standard chemotherapy of carbolatin/paclitaxel was evaluated in two phase III trials demonstrating a significant improvement in PFS compared to the standard chemotherapy treatment (GOG 218 and ICON 7). Table 1 provides an overview of all published phase II and III studies (Table 1).

Treating ovarian cancer patients with bevacizumab single agent regimens demonstrated very promising reponse rates (Table 1), furthermore some combined therapies including cytotoxic drugs seemed to enhance not only direct antitumoral efficacy but also antiangiogenic potentials. This is in particular the case for so called metronomic treatment strategies, where chemotherapeutic agents are administered in low dosages in regular, short time intervals, for example, cyclophosphamide in daily oral application (SanchezMunoz et al., 2010).

The main toxic effects of bevacizumab as documented in the available trials are hypertension, headache, proteinuria, thrombosis and hemoptysis (Table 1). A particular attention has been drawn on GI perforations that have been observed and seem to be a specific phenomenon on bevacizumab-therapies in patients with EOC. The exact pathomechanism of this potentially fatal complication is not fully understood though there are several explaining theories (Richardson et al., 2010). Currently, the average risk of developing a GI perforation during bevacizumab-therapy can be estimated at 7-8 \% for patients with EOC (Richardson et al., 2010, Tanyi et al., 2011).

\section{VEGF trap}

VEGF trap (aflibercept ${ }^{\circledR}$ ), a molecular fusion protein, inhibits VEGF-mediated events as a high affinity VEGF decoy. It is also able to bind to other VEGF familiy members e.g. PIGF. Tew et al. published a multicenter phase II study in women with recurrent ovarian cancer who were treated with $2 \mathrm{mg} / \mathrm{kg}$ or $4 \mathrm{mg} / \mathrm{kg}$ aflibercept, but the study only showed a moderate response rate (ORR $7 \%$, Moroney et al., 2009)

Toxic effects of aflibercept are hypertension, headache, fatigue and GI -perforations $(1,8 \%)$. Colombo et al. could show that aflibercept reduces ascites in patients with advanced ovarian cancer. They achieved a response in terms of less often repeated paracenteses.

\section{Ramucirumab}

Ramucirumab (IMC-1121B) is a novel fully human antibody targeting VEGFR2. It showed significant antitumor activity in several mouse tumors and human tumor xenografts by inhibiting angiogenesis mediated by reduction of microvessel density, tumor cell apoptosis and necrosis, as well as a decreased tumor cell proliferation (Prewett et al., 1999; Spratlin, 2011).

Ramucirumab is currently being explored in phase III trials in hepatocellular carcinomas (ImCLON HCC-Ramucirumab), NSCLC (Lilly study I4T-MC-JVB(a)), in previously untreated patients with HER2-negative, unresectable, locally recurrent or metastatic breast cancer (Trio-012) and in patients with metastatic colorectal carcinoma. A phase III study is designed in patients with metastatic adenocarcinoma of the stomach. The safety and efficacy of Ramucirumab is also evaluated in a randomized phase II trial in patients with metastatic melanoma with or without dacarbazine (Carvajal et al., 2010), as second-line therapy in 
patients with locally advanced or metastatic transitional cell carcinoma of the bladder, urethra, ureter, or renal pelvis and metastatic androgen-independent prostate cancer with or without mitoxantrone and prednisone.

At the time of publication, ramucirumab was undergoing assessment in a non-randomized, open-label, multicenter phase II study as a monotherapy in the treatment of persistent or recurrent EOC, FTC, or PPC. Ramucirumab is given at $8 \mathrm{mg} / \mathrm{kg} \mathrm{q} 2 \mathrm{w}$. The results of these trials will tell whether ramucirumab is a useful addition to current antiangiogenic therapies and an option in the treatment of patients with ovarian cancer.

\section{Tyrosine kinase inhibitors}

Tyrosine kinase inhibitors repress the VEGF pathway by binding directly to the VEGFRs.

\section{Sorafenib}

Sorafenib is an oral tyrosine kinase inhibitor which not only targets VEGFR2 and 3 and PDGFR-beta but also the Ras/Raf/Mek/ERK pathways. In the GOG 170 trial Matei et al. evaluated Sorafenib as a single agent treatment in patients with recurrent ovarian cancer. In this phase II trial preliminary results showed a progression free survival for at least six months in 12 of 59 patients, partial response in 2 patients and stable disease in 20 patients. Progressive disease was determined in 30 patients (Matei et al., 2010).

Siu et al. tested Sorafenib in combination with gemcitabine in a phase I trial in solid tumors and could show that the combination was well tolerated (Siu et al., 2006). In contrast to this and in line with Matei et al. Pölcher and colleagues pointed out that sorafenib showed markable toxicity in ovarian cancer study protocols, thus this drug needs to be further evaluated in clinical trials (Pölcher et al., 2010).

\section{Sunitinib}

Sunitinib (Sutent ${ }^{\circledR}$ ) is also an oral tyrosine kinase inhibitor that binds to VEGFR 1-3 as well as PDGFR-alpha and beta. Sunitinib is approved for the treatment of advanced or metastatic renal cell carcinoma as first line therapy, of nonresectable gastrointestinal stromal tumours and for the treatment of patients with unresectable, locally advanced, or metastatic pancreatic neuroendocrine tumors ( $\mathrm{pNET}$ ). There a lots of clinical trials to determine the efficacy and safety of sunitinib in several tumor entities e.g glioblastoma, colon cancer and breast cancer. [http://clinicaltrialsfeeds.org/clinical-trials/results/term=sunitinib]

In a preclinical study sunitinib inhibited tumor growth and reduced peritoneal metastasis of human ovarian cancer in xenografted mice. (Bauerschlag et al., 2010). The following phase II study of sunitinib (initial dose $50 \mathrm{mg} / \mathrm{d}$ p.o) in 30 patients with recurrent EOC or PPC showed only a partial response $(3,3 \%)$. Hand-foot-syndrome, hypertension, fatigue and gastrointestinal symptoms but no gastrointestinal perforation were the main toxicities. (Biagi et al., 2011).

\section{Pazopanib}

Pazopanib is an investigational, oral, angiogenesis inhibitor targeting VEGFR, PDGFR and c-kit. Pazopanib is currently being studied in a number of different tumour types; clinical trials are currently underway in renal cell carcinoma (Phase III), breast cancer (Phase III in inflammatory breast cancer), ovarian cancer, STS, NSCLC, cervical cancer and other solid tumours. It is being evaluated as a monotherapy, in combination with targeted therapies and in combination with cytotoxic chemotherapy. 


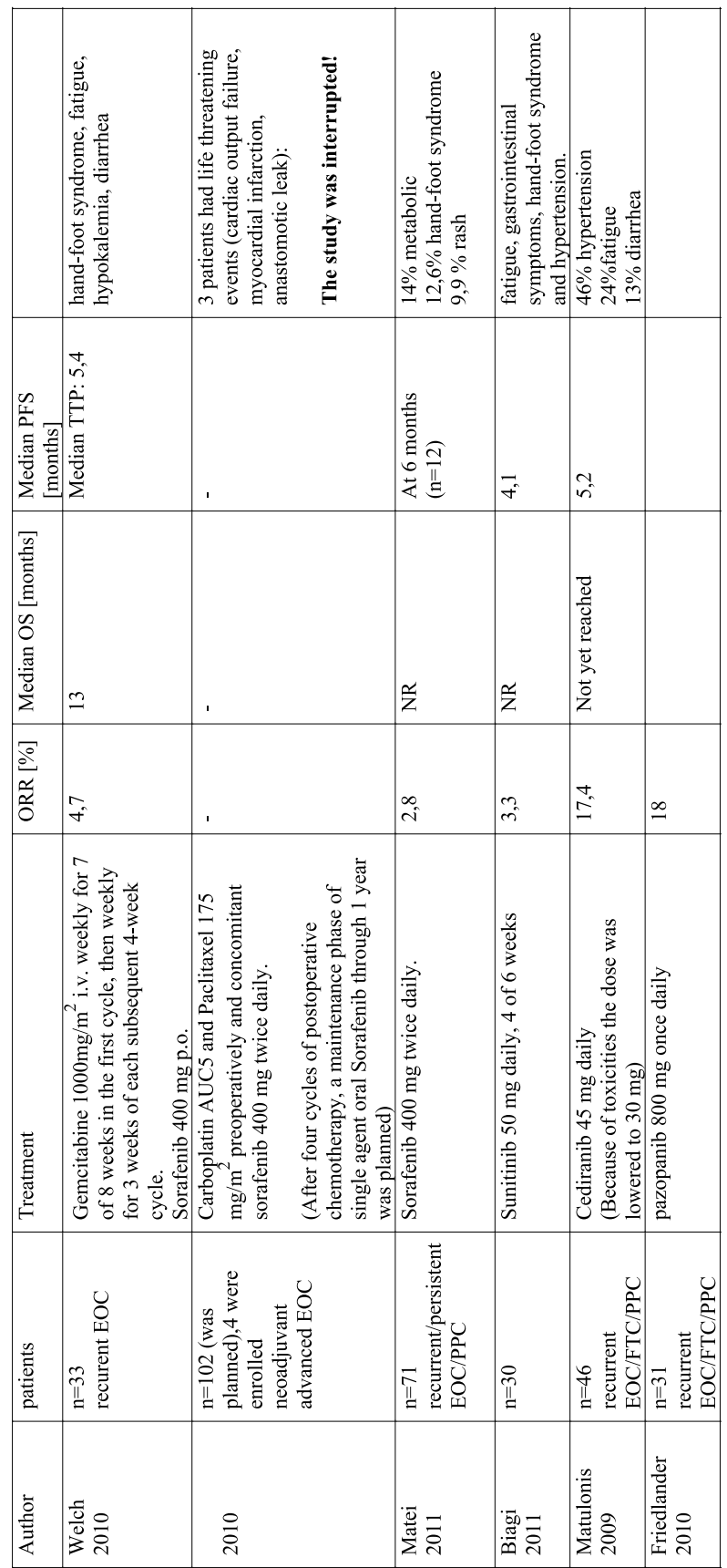

Table 2. Overview of published phase II and phase III trials on bevacizumab in patients with ovarian cancer. 
VEG104450 is a Phase II study to assess the biochemical response rate (determined by CA125 response) to pazopanib monotherapy in subjects with epithelial ovarian, fallopian tube, or primary peritoneal carcinoma that have responded to standard treatment and who have a high risk of recurrence due to a rising CA-125. Data reported recently (Friedlander, 2008) showed that, in 36 ovarian subjects with biochemical (i.e. CA-125) recurrence after < 2 treatment regimens, the most frequent AEs (reported by more than $20 \%$ of subjects) are diarrhoea, fatigue, nausea (all 47\%), hypertension and abdominal pain (31\%), AST and ALT increase $(25 \%)$, anorexia and vomiting $(22 \%)$. These were primarily Grade 1 and 2, with only one Grade 4 event reported in the study (of peripheral oedema, considered unrelated to the study drug); there were no Grade 5 events and no bowel perforations reported in this study. Currently, the German PACOVAR-trial analysis in a phase I/II setting evaluates activity and tolerability of pazopanib combined with orally administered metronomic cyclophosphamide in patients with recurrent, intensively pretreated ovarian cancer. First results of the phase I are expected in 2012.

\section{Endometrial cancer}

Endometrial cancer is the most common gynecologic malignancy with a peak incidence between the ages of 55 and 65 . Worldwide about 142.000 women are affected by endometrial cancer every year (Jemal et al., 2010). It is frequently diagnosed at an early stage as women affected often present by abnormal vaginal bleeding. At an early stage endometrial cancer can be treated surgically with curable intention (van Wijk et al., 2009). In patients with highrisk endometrial cancer postoperative pelvic radiotherapy, adjuvant radiation therapy or adjuvant chemotherapy have shown to improve outcome (Ray et al., 2009).

However, about $13 \%$ of all patients with endometrial cancer develop recurrent disease. (Van Wijk et al., 2009). In the treatment of recurrent endometrial cancer different therapeutic modalities consisting of radiotherapy, surgery and systemic therapies as chemotherapy and hormone therapy are in use (Ray et al., 2009). Clinical trials evaluating chemotherapeutic regimen for patients with endometrial cancer include combinations of doxorubicin and cisplatin, cyclophosphamide or paclitaxel and carboplatin, most of them administered in palliative situation (Ray et al., 2009).

Due to promising results of antiangiogenic treatment concepts in many solid tumors, some efforts have already been made to elucidate the role of VEGF in endometrial cancer. Kamat et al. examined serum samples of endometrial cancer patients and established an endometrioid orthotopic mouse model to approach the role of VEGF in endometrial cancer. The authors found significantly increased levels of VEGF in approximately half of the tumors. These high levels were independently associated with a poor outcome of the affected patients, as an overexpression of VEGF enhances tumor growth. Moreover, in a published mouse model study the combination of docetaxel and bevacizumab has proven a greater therapeutic efficacy than docetaxel or bevacizumab alone (Kamat et al., 2005).

Recently, Aghajanian et al published data of a phase II GOG trial of bevacizumab in patients with recurrent or advanced endometrial cancer. In a series of $n=56$ patients the authors could demonstrate that a treatment regimen consisting of $15 \mathrm{mg} / \mathrm{kg}$ bevacizumab i.v. every three weeks led to an ORR of $13.5 \%$ and a PFS at 6 months of $40.4 \%$ (Aghajanian et al., 2010). Furthermore, it could be shown that high VEGF-A immunohistochemical staining in archival tumors was associated with a reduced risk of death but that high circulating VEGFA levels were associated with poor outcome. For possible explanation authors suggested that VEGF staining in tumor did not reflect the state of the tumor before treatment when 
VEGF-levels in plasma where measured. Finally, in 2011, Reinhardt and colleagues published a case report presenting the successful remission in a patient with recurrent, heavily pretreated endometrial cancer using a combination regimen with bevacizumab and metronomic cyclophosphamide (Reinhardt et al., 2011). Adverse events of bevacizumab therapies in endometrial cancer patients include GI-hemorrhage, proteinuria, hypertension, thrombosis and pulmonary embolism. So far no GI-perforations or fistulae have been reported (Aganajian et al., 2010)

Beside bevacizumab as antiangiogenic treatment concept the oral tyrosine kinase inhibitors of multiple VEGF receptors sunitinib and sorafenib have been evaluated in clinical studies for the treatment of endometrial cancer.

Sorafenib showed minimal activity with PFS at 6 months of $29 \%$ and median overall survival of 11.4 months. As adverse events hypertension, hand-foot-syndrome, anemia, thrombosis, fatigue and bleeding were found (Nimeiri et al., 2008).

Accordingly, in a phase II study in recurrent or metastatic endometrial cancer sunitinib demonstrated activity with an ORR of $15 \%$ and median overall survival of 19 months. Adverse events were fatigue and hypertension. (Correa et al., 2010)

\section{Cervical cancer}

Cervical cancer is the second most cause of female cancer mortality worldwide with 288000 deaths every year. About 510.000 cases of cervical cancer are reported each year with nearly $80 \%$ in developing countries. Cervical cancer is preventable and generally curable if diagnosed at early stage (Wright et al., 2006). Surgery is the goldstandard in early lesions, whereas locally advanced lesions are managed with concurrent cisplatin chemotherapy and pelvic radiation (Monk et al., 2009). Metastatic disease or recurrent lesions not amenable to radical local excision or regional radiation are treated with palliative chemotherapy (Tewari et al., 2009). Patients diagnosed with locally advanced or metastatic cancer of the cervix have a very poor prognosis with a 5-year survival between 5 and $15 \%$ (patients with stage IV disease) (Takano et al., 2009).

Recurrent tumors within the irradiated and therefore devascularized fields likely have microenvironment changes that make chemotherapy delivery far from optimal. For these reasons, this patient population is not one that is ideally suited to receive multiple lines of chemotherapy. Biologic therapies offer another therapeutic strategy that has demonstrated effectiveness in tumors resistant to chemotherapy (Monk et al., 2010).

Angiogenesis seems to play an important role in the development and progression of cervical cancer. Evidence that angiogenesis plays an important role in locally advanced cervical cancer has been shown in recent years (Mackay et al., 2010; Carpini et al., 2010). In one study of 111 patients with cervical cancer, Cooper et al identified tumor angiogenesis (as reflected by the tumor microvessel density) as a significant prognostic factor within a Cox multivariate analysis, where it was associated with poor locoregional control and overall survival. Data from prospective studies in women with advanced cervical cancer, treated with anti-angiogenic therapy, are limited to a few small studies.

\section{Bevacizumab}

Corresponding to other solid tumors, most experiences are also reported in targeting VEGF with bevacizumab.

Wright et al first evaluated the effect of the VEGF-Inhibitor bevacizumab in a retrospective trial in women with recurrent cervical cancer (Wright et al., 2006). Five patients were treated 
with bevacizumab and 5-fluoruracil, one patient with bevacizumab and capecitabine, respectively. The median age of these patients was 43 years, the stage distribution was IB2, IIB and IIIB at 2 patients a throw. All of the patients had received prior platinum-based chemotherapy. Bevacizumab was given intravenously every other week to five of the six patients with a starting dose of either $5 \mathrm{mg} / \mathrm{kg}$ or $10 \mathrm{mg} / \mathrm{kg}$. One patient was given bevacizumab at a dose of $15 \mathrm{mg} / \mathrm{kg}$ every three weeks. A total of 30 doses of bevacizumab was given. The regimen was well tolerated. There was a grade 4 neutropenic sepsis encountered in one patient after 2 cycles of bevacizumab and one extremity thrombosis in another subject. The overall response rate (ORR) was $33 \%$ (2 of the 6 patients). One of these patients showed a complete response, the other one a partial response. There was a stable disease in two patients (33\%). The median time to progression for the four patients with clinical benefit (CR, PR, SD) was 4.3 months. None of the patients demonstrated a progression free intervall $>6$ months. Though only a small number of patients was observed, this study indicated that the combination of bevacizumab and 5-fluoruracil-based chemotherapy seems to be feasible and associated with significant activity in patients with recurrent cervical cancer.

In 2009 Monk published a phase II-trial of bevacizumab in the treatment of persistent in recurrent squamous cell carcinoma of the cervix (GOG protocol 227C) (Monk et al., 2009).

46 patients were randomized to the trial and received bevacizumab in a dose of $15 \mathrm{mg} / \mathrm{kg}$ intravenously every 3 weeks. Primary endpoints of the study were PFS for at least 6 months and evaluation of adverse events. A total of 254 cycles of bevacizumab as a single agent therapy were administered with a median of 4 cycles per patient. Eleven patients $(23.9 \%)$ experienced a progression free survival of $>6$ months, whereas five patients $(10.9 \%)$ showed partial responses. Median overall survival for all patients was 7.29 months. There were several grade $3 / 4$ adverse events demonstrated in this trial, including hypertension $(n=7)$, thromboembolism $(n=5)$, gastrointestinal complaints $(n=4)$, anemia $(n=2)$, vaginal bleeding $(n=1)$, neutropenia $(n=1)$ and fistula $(n=1)$ No unusual toxicities were noted. This trial provided that bevacizumab as a single agent therapy was relatively well tolerated, safe and demonstrated remarkable activity. Importantly, the results of this protocol constitute the first prospective clinical trial of a biologic agent that shows clinical activity in cervical cancer (Tewari et al., 2009). Exploratory analyses suggested an increased risk of progression (or death) for those who are African- American, are young, and have a poor performance status. Additional analyses also suggested an increased risk of death for those who have more prior chemotherapy regimens.

Takano et al (Takano et al., 2009) reported of two cases of patients with cervical cancer treated with bevacizumab $(2 \mathrm{mg} / \mathrm{kg})$, paclitaxel $(80 \mathrm{mg} / \mathrm{m} 2)$ and carboplatin $(\mathrm{AUC}=2.0)$. Therapy consisted of carboplatin/paclitaxel weekly on days 1, 8, 15 and bevacizumab weekly on days $1,8,15,21$, q28d. In both patients full remission was notified and there was no evidence of disease for $>10$ months as well as no adverse events higher than grade 3 .

Based on the findings in the studies described, a phase III trial with bevacizumab for treatment of cervical cancer is planned by the GOG. In GOG 240, patients will be randomized to one of four regimens: paclitaxel/cisplatin, paclitaxel/cisplatin plus bevacizumab, paclitaxel/topotecan and paclitaxel/topotecan plus bevacizumab.

Also, other anti-angiogenesis compounds will soon be investigated by the GOG. For example, brivanib, a highly potent dual inhibitor of VEGFR and fibroblast growth factor receptor (FGFR) will be under study (Monk et al., 2010). 


\section{Sunitinib}

There is one phase II study published in 2010 by Mackay et al. that evaluates the activity of sunitinib, a tyrosine kinase inhibitor in the treatment of locally advanced or metastatic cervical cancer (Mackay et al., 2010) (NCIC CTG Trial IND.184). Sunitinib is an oral, multitargeted tyrosine kinase inhibitor, that inhibits receptors for VEGF, c-Kit and plateletderived growth factor. 19 patients received sunitinib at a dose of $50 \mathrm{mg} /$ day in 6-week cycles (4 weeks, followed by 2 weeks off treatment). 16 patients (84\%) showed stable disease, but there was no objective response noted in any of the patients. However, 4 patients developed fistulae during treatment and one patient had an enterocutaneous fistula 3.5 months post-study. All of the fistulae occured within the previous radiation fields. Although SD-rate was $84 \%$, the overall progression free survival was only 3.5 months in this study, which compares with the progression free survival in the phase II trial published by Monk and described before. But the observation of five cases of fistulae (26\%) was of particular concern, so that sunitinib as a single agent therapy does not have enough sufficient activity in women with advanced cervical cancer to recommend further study.

\section{Conclusion and future perspectives}

There is consensus that angiogenesis is a crucial phenomenon in the progression of gynecologic tumors. Many promising efforts have been made so far demonstrating that ovarian cancer as well as uterine cancers can be targeted by antiangiogenic treatment strategies.

As gynecologic tumors still often respond very differently to antiangiogenic therapies future studies will have to work on identifying patients that will likely respond to specific antiangiogenic regimens. Existing and already proven active therapies will have to be confirmed in further long-term experiences, in particular regarding their potential longterms toxicity or side-effects and finally new, additional targets beyond the VEGF/ VEGFRmechanism have to be evaluated. Finally, a new attention should be paid to the concept of maintenance treatments, in particular in EOC, as antiangiogenic treatment concepts, might be especially useful in keeping a major cytotoxic therapeutic success. A particular role may be attributed in the future to combined antiangiogenic and metronomic cytotoxic regimens.

\section{References}

Aghanjanian C, Sill MW, Darcy KM, Greer B, McMeekin DS, Rose PG, et al: Phase II Trial of Bevacizumab in Recurrent or Persistent Endometrial Cancer: A Gynecologic Oncology Group Study.J ClinOncol, 2010.

Bauerschlag DO, Schem C, Tiwari S, Egberts JH, Weigel MT, Kalthoff H, Jonat W, Maass N, Meinhold-Heerlein I.Sunitinib (SU11248) inhibits growth of human ovarian cancer in xenografted mice. Anticancer Res. 2010 Sep;30(9):3355-60.

Biagi JJ, Oza AM, Chalchal HI, Grimshaw R, Ellard SL, Lee U, Hirte H, Sederias J, Ivy SP, Eisenhauer EA. A phase II study of sunitinib in patients with recurrent epithelial ovarian and primary peritoneal carcinoma: an NCIC Clinical Trials Group Study.Ann Oncol. 2011 Feb;22(2):335-40. Epub 2010 Aug 12.

Bryant CS, Munkarah AR, Kumar S, Batchu RB, Shah JP, Berman J, Morris RT, Jiang ZL, Saed GM. Reduction of hypoxia-induced angiogenesis in ovarian cancer cells by 
inhibition of HIF-1 alpha gene expression.Arch Gynecol Obstet. 2010 Dec;282(6):677-83. Epub 2010 Feb 7.

Burger RA. Overview of anti-angiogenic agents in development for ovarian cancer.Gynecol Oncol. 2011 Apr;121(1):230-8. Epub 2011 Jan 8. Review.

Carvajal et al. J Clin Oncol 28:15s, 2010 (suppl; abstr 8519 Carpini, J.D., A.K. Karam, and L. Montgomery, Vascular endothelial growth factor and its relationship to the prognosis and treatment of breast, ovarian, and cervical cancer.Angiogenesis, 2010.13(1): p. 43-58.

Correa R, Mackay H, Hirte HW, et al: A phase II study of sunitinib in recurrent or metastatic endometrial carcinoma: A trial of the princess MargaretHospital, The University of Chicago, and California Cancer Phase II Consortia.J ClinOncol 28:399s, 2010 (suppl; abstr 5038)

Delli Carpini J, Karam AK, Montgomery L.Vascular endothelial growth factor and its relationship to the prognosis and treatment of breast, ovarian, and cervical cancer.Angiogenesis. 2010 Mar;13(1):43-58. Epub 2010 Mar 14. Review. Erratum in: Angiogenesis. 2010 Sep;13(3):279. Carpini, Jennifer Delli [corrected to Delli Carpini, Jennifer].

Fagotti A, Gallotta V, Romano F, Fanfani F, Rossitto C, Naldini A, Vigliotta M, Scambia G. Peritoneal carcinosis of ovarian origin. World J Gastrointest Oncol. 2010 Feb 15;2(2):102-8.

Ferrara N, Gerber HP, LeCouter J. The biology of VEGF and its receptors. Nat Med. 2003 Jun;9(6):669-76. Review.

Folkman J. The biology of VEGF and its receptors. Tumor angiogenesis: therapeutic implications. N Engl J Med. 1971 Nov 18;285(21):1182-6. Review.

Friedlander M, Hancock KC, Rischin D, Messing MJ, Stringer CA, Matthys GM, Ma B, Hodge JP, Lager JJ. A Phase II, open-label study evaluating pazopanib in patients with recurrent ovarian cancer.

Gynecol Oncol. 2010 Oct;119(1):32-7. Epub 2010 Jun 27. Jemal A, Siegel R, Xu J, Ward E Cancer Stratistics CA Cancer J Clin. 2010 Sep-Oct;60(5):277-300. Epub 2010 Jul 7. Erratum in: CA Cancer J Clin. 2011 Mar-Apr;61(2):133-4.

Kamat AA, Merrit WM, Coffey D, Lin YG, Patel PR, et al: Clinical and Biological Significance of Vascular Endothelial Growth Factor in Endometrial Cancer.ClinCancer Res 2007; 13(24)

Mackay, H.J., Tinker, A., Winquist, E., Thomas, G., Swenerton, K., Oza, A., Sederias, J., Ivy, P. and Eisenhauer, E.A. A phase II study of sunitinib in patients with locally advanced or metastatic cervical carcinoma: NCIC CTG Trial IND. 184.Gynecologic oncology, 2010.116(2): p. 163-167.

Matei D, Sill MW, Lankes HA, DeGeest K, Bristow RE, Mutch D, Yamada SD, Cohn D, Calvert V, Farley J, Petricoin EF, Birrer MJ. Activity of sorafenib in recurrent ovarian cancer and primary peritoneal carcinomatosis: a gynecologic oncology group trial. J Clin Oncol. 2011 Jan 1;29(1):69-75. Epub 2010 Nov 22.

McGuire WP, Brady MF, and Ozols RF: The Gynecologic Oncology Group experience in ovarian cancer. Ann Oncol (1999)10: S29-34.

McGuire WP: Primary therapy of epithelial ovarian cancer. Amer Soc Clin Oncol Educational Book (Spring 2001) 477-480. 
Monk, B.J., Sill, M.W., Burger, R.A., Gray, H.J., Buekers, T.E. and Roman, L.D. Phase II trial of bevacizumab in the treatment of persistent or recurrent squamous cell carcinoma of the cervix: a gynecologic oncology group study.Journal of Clinical Oncology, 2009.27(7): p. 1069.

Monk, B.J., L.J. Willmott, and D.A. Sumner, Anti-angiogenesis agents in metastatic or recurrent cervical cancer.Gynecologic oncology, 2010.116(2): p. 181-186.

Moroney JW, Sood AK, Coleman RL. Aflibercept in epithelial ovarian carcinoma. Future Oncol. 2009 Jun;5(5):591-600. Review.

Nimeiri HS, Oza AM, Morgan RJ, et al :Sorafenib in patients with advanced/recurrent uterine carcinoma or carcinosarcoma: A phase II trial of the university of chicago, PMH, and California Phase II Consortia.J ClinOncol. 26:313s, 2008 (suppl; abstr 5585)

Parmar MK, Ledermann JA, Colombo N, du Bois A, Delaloye JF, Kristensen GB, Wheeler S, Swart AM, Qian W, Torri V, Floriani I, Jayson G, Lamont A, Tropé C; ICON and AGO Collaborators.

Paclitaxel plus platinum-based chemotherapy versus conventional platinum-based chemotherapy in women with relapsed ovarian cancer: the ICON4/AGO-OVAR2.2 trial. Tumor angiogenesis: therapeutic implications.

Pölcher M, Eckhardt M, Coch C, Wolfgarten M, Kübler K, Hartmann G, Kuhn W, Rudlowski C. Sorafenib in combination with carboplatin and paclitaxel as neoadjuvant chemotherapy in patients with advanced ovarian cancer. Cancer Chemother Pharmacol. 2010 May;66(1):203-7. Epub 2010 Mar 5.

Prewett M, Huber J, Li Y, Santiago A, O'Connor W, King K, Overholser J, Hooper A, Pytowski B, Witte L, Bohlen P, Hicklin DJ. Antivascular endothelial growth factor receptor (fetal liver kinase 1) monoclonal antibody inhibits tumor angiogenesis and growth of several mouse and human tumors. Cancer Res. 1999 Oct 15;59(20):520918

Ray M. and Fleming G, Management of advanced-stage and recurrent endometrial cancer.SeminOncol, 2009. 36(2): p. 145-54.

Reinhardt J, Schott S, Mayer C, Sohn C, Eichbaum M Long-term remission of an advanced recurrent endometrial cancer in a heavily pretreated patient using a combined regimen with bevacizumab and metronomic cyclophosphamide. Anticancer Drugs. 2011 Mar 2. [Epub ahead of print]

Richardson DL, Backes FJ, Hurt JD, Seamon LG, Copeland LJ, Fowler JM, Cohn DE, O'Malley DM. Which factors predict bowel complications in patients with recurrent epithelial ovarian cancer being treated with bevacizumab? Gynecol Oncol. 2010 Jul;118(1):47-51. Epub 2010 Apr 10 Spratlin J.

Ramucirumab (IMC-1121B): Monoclonal antibody inhibition of vascular endothelial growth factor receptor-2. Curr Oncol Rep. 2011 Apr;13(2):97-102.

Sánchez-Muñoz A, Mendiola C, Pérez-Ruiz E, Rodríguez-Sánchez CA, Jurado JM, AlonsoCarrión L, Ghanem I, de Velasco G, Quero-Blanco C, Alba E. Bevacizumab plus low-dose metronomic oral cyclophosphamide in heavily pretreated patients with recurrent ovarian cancer. Oncology. 2010;79(1-2):98-104. Epub 2010 Nov 15.

Siu LL, Awada A, Takimoto CH, Piccart M, Schwartz B, Giannaris T, Lathia C, Petrenciuc O, Moore MJ. Phase I trial of sorafenib and gemcitabine in advanced solid tumors with 
an expanded cohort in advanced pancreatic cancer. Clin Cancer Res. 2006 Jan 1;12(1):144-51.

Takano, M., Kikuchi, Y., Kita, T., Goto, T., Yoshikawa, T., Kato, M., Watanabe, A., Sasaki, N., Miyamoto, M. and Inoue, H. Complete remission of metastatic and relapsed uterine cervical cancers using weekly administration of bevacizumab and paclitaxel/carboplatin.Onkologie, 2009.32(10): p. 595-597.

Tanyi JL, McCann G, Hagemann AR, Coukos G, Rubin SC, Liao JB, Chu CS. Clinical predictors of bevacizumab-associated gastrointestinal perforation. Gynecol Oncol. 2011 Mar;120(3):464-9. Epub 2010 Dec 17.

Tew WP, Gordon M, Murren J, Dupont J, Pezzulli S, Aghajanian C, Sabbatini P, Mendelson D, Schwartz L, Gettinger S, Psyrri A, Cedarbaum JM, Spriggs DR.Phase 1 study of aflibercept administered subcutaneously to patients with advanced solid tumors. Clin Cancer Res. 2010 Jan 1;16(1):358-66. Epub 2009 Dec 22.

Tewari, K.S. and B.J. Monk. Recent achievements and future developments in advanced and recurrent cervical cancer: trials of the Gynecologic Oncology Group. inSeminars in Oncology. 2009: Elsevier.

Teoh DG, Secord AA. Antiangiogenic therapies in epithelial ovarian cancer. Cancer Control. 2011 Jan;18(1):31-43. Review.

Van Wijk FH, van der Burg MEL, Burger CW, Vergote I, van Doorn HC., Management of recurrent endometrioid endometrial cancer: an overview.Int J Gynecol Cancer, 2009. 19(3): p. 314-20.

Wright, J.D., Viviano, D., Powell, M.A., Gibb, R.K., Mutch, D.G., Grigsby, P.W. and Rader, J.S Bevacizumab combination therapy in heavily pretreated, recurrent cervical cancer.Gynecologic oncology, 2006.103(2): p. 489-493.

Zweifel M, Jayson GC, Reed NS, Osborne R, Hassan B, Ledermann J, Shreeves G, Poupard L, Lu SP, Balkissoon J, Chaplin DJ, Rustin GJ. Phase II trial of combretastatin A4 phosphate, carboplatin, and paclitaxel in patients with platinum-resistant ovarian cancer. Ann Oncol. 2011 Jan 27. [Epub ahead of print] 


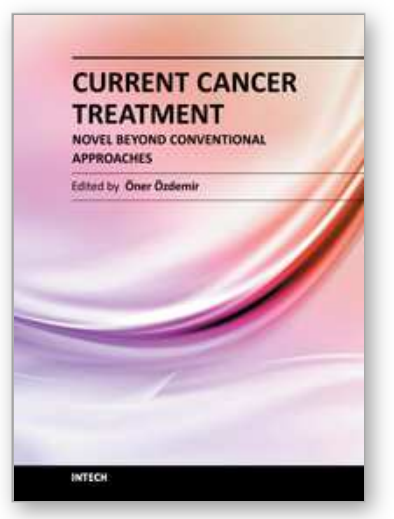

\author{
Current Cancer Treatment - Novel Beyond Conventional \\ Approaches \\ Edited by Prof. Oner Ozdemir
}

ISBN 978-953-307-397-2

Hard cover, 810 pages

Publisher InTech

Published online 09, December, 2011

Published in print edition December, 2011

Currently there have been many armamentaria to be used in cancer treatment. This indeed indicates that the final treatment has not yet been found. It seems this will take a long period of time to achieve. Thus, cancer treatment in general still seems to need new and more effective approaches. The book "Current Cancer Treatment - Novel Beyond Conventional Approaches", consisting of 33 chapters, will help get us physicians as well as patients enlightened with new research and developments in this area. This book is a valuable contribution to this area mentioning various modalities in cancer treatment such as some rare classic treatment approaches: treatment of metastatic liver disease of colorectal origin, radiation treatment of skull and spine chordoma, changing the face of adjuvant therapy for early breast cancer; new therapeutic approaches of old techniques: laser-driven radiation therapy, laser photo-chemotherapy, new approaches targeting androgen receptor and many more emerging techniques.

\title{
How to reference
}

In order to correctly reference this scholarly work, feel free to copy and paste the following:

M. Eichbaum, C. Mayer, E. Bischofs, J. Reinhardt, J. Thum and C. Sohn (2011). Antiangiogenic Treatment Concepts in Gynecologic Oncology, Current Cancer Treatment - Novel Beyond Conventional Approaches, Prof. Oner Ozdemir (Ed.), ISBN: 978-953-307-397-2, InTech, Available from:

http://www.intechopen.com/books/current-cancer-treatment-novel-beyond-conventionalapproaches/antiangiogenic-treatment-concepts-in-gynecologic-oncology

\section{INTECH}

open science | open minds

\section{InTech Europe}

University Campus STeP Ri

Slavka Krautzeka 83/A

51000 Rijeka, Croatia

Phone: +385 (51) 770447

Fax: +385 (51) 686166

www.intechopen.com

\section{InTech China}

Unit 405, Office Block, Hotel Equatorial Shanghai

No.65, Yan An Road (West), Shanghai, 200040, China

中国上海市延安西路65号上海国际贵都大饭店办公楼 405 单元

Phone: +86-21-62489820

Fax: $+86-21-62489821$ 
(C) 2011 The Author(s). Licensee IntechOpen. This is an open access article distributed under the terms of the Creative Commons Attribution 3.0 License, which permits unrestricted use, distribution, and reproduction in any medium, provided the original work is properly cited. 